\title{
A Case Report of Hashimoto's Thyroiditis
}

\author{
Lidya Imelda Laksmi ${ }^{1}$, Betty Tan $^{1}$, Jessy Chrestella ${ }^{1}$ \\ ${ }^{1}$ Department of Anatomic Pathology of Medical Faculty, Universitas Sumatera Utara,Jl. Dr. Mansyur \\ No 5 Medan 20155, Indonesia \\ E-mail: lidyaimelda76@gmail.com
}

\begin{abstract}
Background: Hashimoto's thyroiditis is a common lifelong autoimmune disease of the thyroid gland.

Case Presentation: A 63-year-old woman was clinically diagnosed as non toxic goiter. Thyroidectomy was done and specimen was sent for histopathological examination. A brownish and soft mass was received with size $6 \times 5 \times 4 \mathrm{~cm}$. Microscopic examination showed that proliferation of lymphoid follicles with germinal center of lymphoplasmacytic cells between acini. Some of acini were destroyed and atrophic, while some of them formed microfollicular structures. Acini were lined by simple cuboid epithelium with round oval nuclei, fine chromatin, and eosinophilic cytoplasm. Most of acini contained colloid inside lumen. Lying in between acini were found oncocytic cells with round nuclei, some with prominent nucleoli, fine chromatin, abundant and granular cytoplasm. Stroma consisted of fibrous connective tissue.
\end{abstract}

Conclusion: Histopathological examination yielded the diagnosis of Hashimoto's thyroiditis.

Keywords: thyroid, autoimmune, Hashimoto

\section{Introduction}

Thyroiditis can be caused by multiple factors among which autoimmune appears to be the most common etiological factors [1]. One of the autoimmune inflammation occurred in thyroid is chronic thyroiditis (Hashimoto's thyroiditis or autoimmune thyroiditis). This disease was first described by Hakaru Hashimoto in 1912. In 1956, Roitt et al. reported autoantibodies against thyroglobulin in patient's with Hashimoto's thyroiditis. One year later, Trotter et al. (1957) identified a second antigen in the microsomal fraction of thyroid homogenates, which proved to be thyroid peroxidase (TPO) $[1,2]$.

Here, we report the case of a 63year-old woman who was clinically diagnosed as non toxic goiter and submitted to biopsy of Hashimoto's thyroiditis.

\section{Case Report}

A 63-year-old woman was clinically diagnosed as non toxic goiter. Thyroidectomy was done and specimen was sent for histopathological examination. A brownish and soft mass was received with size $6 \times 5 \times 4 \mathrm{~cm}$. Microscopic examination showed that proliferation of lymphoid follicles with germinal center of lymphoplasmacytic cells between acini (Figure 1A-C). Some of acini were destroyed and atrophic, while some of them formed microfollicular structures. Acini were lined by simple cuboid epithelium with round oval nuclei, fine chromatin, and eosinophilic cytoplasm (Figure 1D). Most of acini contained colloid inside lumen. Lying in between acini were found oncocytic cells with round nuclei, some with prominent nucleoli, fine chromatin, abundant and granular cytoplasm (Figure 1D). Stroma consisted of fibrous connective tissue. Some blood vessels were congested and interstitial bleeding was found. Histopathological examination yielded the diagnosis of Hashimoto thyroiditis. 


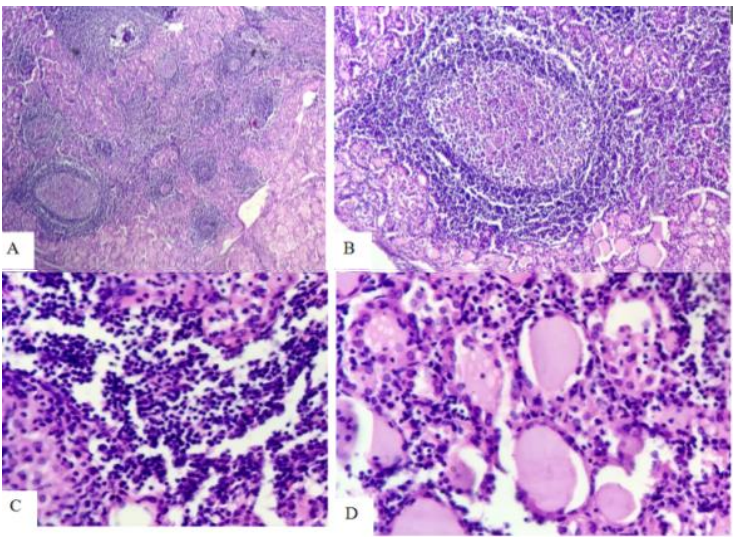

Figure 1. A-C. Proliferation of lymphoid follicles with germinal center of lymphoplasmacytic cells between acini $(x 40$, $x 100, x 400, H E)$. D. Oncocytic cells $(x 400$, HE).

\section{Discussion}

Hashimoto's thyroiditis is a thyroid specific autoimmune disorder in which both humoral and cellular immune mechanisms play a role $[1,3]$. This disease occurs predominantly in middle-aged women (most commonly presenting in the fourth and fifth decades of life) and in children [1,3-6]. Up to 5\% of first-degree relatives of patients with Hashimoto's thyroiditis may have positive antithyroid antibodies in the serum [1,3]. Hashimoto's thyroiditis may also co-exist with other autoimmune diseases including pernicious anemia, diabetes mellitus, and etc. Patients with Hashimoto thyroiditis are at increased risk of developing malignant lymphoma, and this risk has been estimated to be up to 80-fold [6]. Our patient was 63-year-old woman who was clinically diagnosed as non toxic goiter. Her age was older than usual case. Unfortunately, due to limited medical record, we didn't have any information about other diseases that she might suffer from.

Patients frequently have no symptoms when it is found on ultrasound examination [7]. The diagnosis is usually established by a constellation of clinical features and serologic test results. Most common autoantibodies that are tested are anti-thyroglobulin antibodies $(\mathrm{TgAb})$ and TPO antibodies [TPOAb] [6]. This will impair the production of $\mathrm{T} 3$ and $\mathrm{T} 4$. Eventually, these cellular reactions result in the infiltration of lymphocytes and resultant fibrosis, which decreases the number and efficiency of individual follicles [4]. We also didn't have any information about imaging and laboratory results.

Thyroid glands typically show diffuse enlargement, which is usually symmetrical. The gland feels firm and rubbery. The cut surface is usually paler than the normal red-brown color, reflecting the infiltration by lymphocytes and loss of follicular tissue $[1,6]$.

In histologic sections, the thyroid is infiltrated with lymphocytes and plasma cells that may also form lymph follicles with germinal centers. The lymphoplasmacytic infiltration is diffuse but variable in its intensity and effacement of the follicles [1-3,6-8]. The acini are often destroyed or atrophic (see Fig. 2A). A major component of the disease is the presence of oncocytes (Hürthle cells). The oncocytes may line glandular structures or form solid sheets of various sizes. The characteristic features of oncocytes (abundant, eosinophilic, granular cytoplasm and large, often pyknotic nuclei of variable sizes), are usually found in Hashimoto's thyroiditis. The oncocytic cells may show nuclear enlargement and cytologic atypia (see Fig. 2B) [1]. Sometimes, the Hürthle cells appear as single large cells in otherwise normal follicular epithelium. The term Askanazy cells is sometimes used to describe this feature [1-3,6,7]. Fibrosis of variable extent and lymphocytic infiltration are found in the interstitial tissue [2]. In addition, there may be varying degrees of fibrosis and foci of squamous metaplasia associated within the atrophic follicles [1]. 


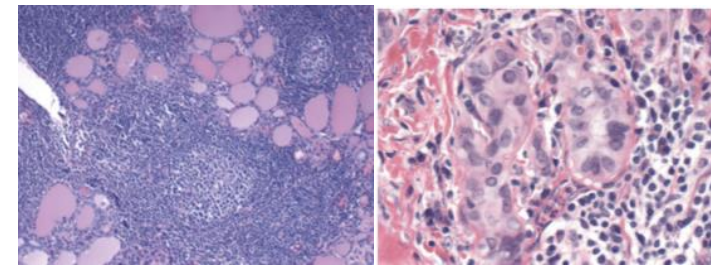

Figure 2. A. Follicular atrophy and infiltration of the gland by lymphocytes and plasma cells with formation of germinal centers. B. Nuclear atypia in Hurthle cells. The cells show nuclear enlargement, nuclear grooves, and powdery chromatin. There is some crowding and overlapping (H\&E stain, X100, X400) [6,9].

Because the histopathologic examination showed specific signs of Hashimoto's thyroiditis, we confirmed the diagnosis as Hashimoto's thyroiditis.

\section{References}

[1] Heilo A, Sigstad E, Groeholt K, (eds.). Chapter 11 Thyroiditis. In: Atlas of Thyroid Lesions. New York: Springer Science+Business Media, 2011.P223-241.

[2] Amino N, Lazarus JH, De Groot LJ. Chapter 86 Chronic Hashimoto Thyroiditis. In: Jameson JL., et al. Part 7 Thyroid. Endocrinology: Adult and Pediatric, Seventh Edition. Philadephia: Elsevier Saunders, 2016. P1515-27.

[3] Loevner LA. Chapter 41 Anatomy and Pathology of the Thyroid and Parathyroid Glands. In: Som PM, and Curtin HD. Head and Neck Imaging, Fifth Edition. China: Mosby Elsevier, 2011. P2629-30.

[4] Smith PW, Hanks LR, Salomone LJ, Hanks JB. Section VIII Endocrine. Chapter 36 Thyroid. In: Townsend CM, Beauchamp RD, Evers BM, Mattox KL, (eds.). Sabiston Textbook of Surgery, Twentieth Edition. Canada: Elsevier, 2017. P891.

[5] Ali SZ, Cibas ES. The Bethesda System for Reporting Thyroid Cytopathology: Definitions, Criteria and Explanatory Notes. Newyork: Springer Science+ Business Media, 2010. P27-30.

[6] Khan A, Nose V. Chapter 9 Pathology of Thyroid Gland. In: Llyod RV. Endocrine Pathology: Differential Diagnosis and Molecular Advances. New York: Springer, 2010. P 189-91.

[7] Kumar V, Abbas AK, Fausto N, Aster JC. Chapter 24 The Endocrine System. China: Saunders, 2010.

[8] Li Y, et al. Distinct Histopathological Features of Hashimoto's Thyroiditis with Respect to IgG4Related Disease. Modern Pathology. 2012;
25:1086-97.

[9] Sanchez MA, Stahl RE. Chapter 30 The Thyroid, Parathyroid, and Neck Masses Other than Lymph Nodes. In: Koss LG, Melamed MR. Koss' Diagnostic Cytology and Its Histopathologic Bases, $5^{\text {th }}$ Edition. Newyork: Lippincott Williams \& Wilkins, 2006. P1155-8. 